\title{
Molecular and biochemical characterization of Tunisian patients with glycogen storage disease type III
}

Amira Mili, Ilhem Ben Charfeddine, Ons Mama, Sonia Abdelhak, Labiba Adala, Abdelbasset Amara, Serena Pagliarani, Sabrina Lucchiarri, Abdelkarim Ayadi, Neji Tebib, Abdelaziz Harbi, Jihene Bouguila, Dorra H’Mida, Ali Saad, Khalifa Limem, GP Comi and Moez Gribaa

Journal of Human Genetics (2012) 57, 221; doi:10.1038/jhg.2012.3

Correction to: Journal of Human Genetics (2012) 57, 170-175; doi:10.1038/jhg.2011.122; published online 17 November 2011

Since the advance online publication of this article, the authors of the above paper have noticed errors in the author list. The spelling of Sabrina Lucchiari was wrong and Sonia Abdelhak was erroneously attributed to this work. It was Dr Wafa Cherif from Dr Abdelhak's laboratory who should have been attributed.
We have replaced Dr Abdelhak's name with Dr Wafa Cherif and corrected wrong spelling of Sabrina Lucchiari. Article with correct author list now appears in this issue. The online html and pdf versions have also been rectified, and now carry the correct names.

The authors would like to apologize for any inconvenience caused. 